\title{
Effect of parenting intervention through "Care for Child Development guideline" on early child development and behaviors: A randomized controlled trial
}

Maryam Bemanalizadeh

Isfahan University of Medical Science

Negin Badihian

Isfahan University of Medical Science

Mehri Khoshhali

Isfahan University of Medical Science

Shervin Badihian

Johns Hopkins University School of Medicine

Neda Hosseini

Isfahan University of Medical Sciences

Marziye Purpirali

Isfahan University of Medical Science

Mansoore Abadian

Isfahan University of Medical Sciences

Omid Yaghini ( $\nabla$ omidyaghini@yahoo.com )

Isfahan University of Medical Science

Seyedeh Shahrbanoo Daniali

Isfahan University of Medical Science

Roya Kelishadi

Isfahan University of Medical Science

\section{Research Article}

Keywords: Child Development, Child Behavior, Parenting Education

Posted Date: February 28th, 2022

DOI: https://doi.org/10.21203/rs.3.rs-1363214/v1

License: (c) (1) This work is licensed under a Creative Commons Attribution 4.0 International License.

Read Full License 
Page $2 / 18$ 


\section{Abstract}

\section{Background}

Several studies showed that parenting intervention programs play a core component in early child development. Considering the limited healthcare resources in developing countries, a group design intervention might be cost-effective.

\section{Methods}

This randomized controlled trial was conducted from February 2020 to February 2021 at an outpatient public Pediatrics clinic in Isfahan, Iran. We included 210 pregnant women aged 18-45 years in their third trimester and followed their children for 18 months. The intervention group underwent 5 educational group sessions, each lasting for almost 45 minutes. The main outcomes were the children's development and behaviors based on Bayley Scales of Infant and Toddler Development-III (BSCID-III) at 12 months and Children Behavior Checklist (CBCL) at 18-month of age.

\section{Results}

Overall, data of 181 children were included in the current study, including 80 in the intervention group and 101 controls. The adjusted median differences were significantly lower in the intervention group than in controls for attention problems $(-3.38 ; \mathrm{SE}=1.59 ; \mathrm{P}=0.035)$, anxiety problems $(-2.28 ; \mathrm{SE}=1.03 ; \mathrm{P}=0.007)$ and pervasive developmental problems $(-5 ; \mathrm{SE}=1.16 ; \mathrm{P}<0.001)$ based on $\mathrm{CBCL}$ results. However, the difference of proportions was not significant in none of the BSCID-III domains in the intervention and control groups.

\section{Conclusion}

In this study, parenting interventions through CCD group sessions were significantly effective on several child's behavior domains, but not on children's development. Although CCD is known to improve children's development and behaviors, the feasible method of its delivery to a large population, especially in developing countries, remains to be determined.

\section{Trial Registration}

IRCT20190128042533N2, Date of registration: 16/01/2020, www.irct.ir

\section{Introduction}

It is estimated that 250 million children aged under five are at risk of not reaching their full developmental potential all around the world (1-3). The term "nurturing care" was coined as a core component of what is required to achieve optimal development in the early years of life, when the brain is developing and the child is more responsive to interventions(4). Parents need to be supported by educational health services 
to have the necessary knowledge and skills, as they are at the forefront of providing nurturing care for promoting early child development (ECD). The WHO/UNICEF intervention on Care for Child Development (CCD) made broad, evidence-based recommendations for how to improve ECD (5). Several studies revealed the effect of parenting interventions on different child's developmental domains such as cognitive, language, socio-emotional, and motor development (6-10) as well as child's behavior such as externalizing and internalising behaviors $(11-14)$. However, the majority of studies, specifically on the child's behavior, were conducted in high-income countries. Evidence showed that parents and children in low-middle income countries or middle-income countries are more susceptible to be exposed to additional risk factors that affect nurturing care and ECD. Low parental education, malnutrition, and fewer early learning opportunities are its commonest determinants. Thus, such support for parenting may be more beneficial in low or middle- resource contexts $(3,15)$. Considering the limited healthcare resources in developing countries, we tried to assess the effect of parenting interventions in a cost-effective setting through CCD interventions on children's development and behaviors to scale up action on child's mental health in Iran as a country located in the Eastern Mediterranean Region.

\section{Methods}

\section{Study Participants}

This randomized controlled trial was approved by the ethics committee of Isfahan University of Medical Sciences (ID: IR.MUI.RESEARCH.REC.1397.092), registered in the Iranian Registry of Clinical Trials ( IRCT20190128042533N2, Date of registration: 16/01/2020) and has therefore been performed in accordance with the ethical standards laid down in the 1964 Declaration of Helsinki and its later amendments. It was conducted from February 2020 to February 2021 at an outpatient public Pediatrics clinic in Isfahan, Iran. To calculate the sample size, we used the equation for comparing two means with type I error of 1.96 and power of 0.90 . Assumptions in two groups (including effect size equal to 0.40 ) were pre-specified on the basis of previously published data and the expected effect was hypothesized as a clinically meaningful effect. We hypothesized that an equivalent outcome will be observed in both groups. The sample size was calculated as at least 133 patients in each group. However, due to COVID-19 pandemic and social restriction, we stopped the study when 228 participants had enrolled. We included Iranian pregnant women aged 18-45 years in their third trimester (days 196 to 280 of pregnancy) who had a healthy fetus based on clinical and ultrasound evaluations, then we followed their children for 18 months. We excluded participants who were absent for more than 2 educational sessions, refused to continue the study, as well as those who had a child with congenital anomaly, birth asphyxia, seizure, or with known metabolic or neurological disorders after birth.

\section{Study Design}

The study protocol was explained to participants and written informed consent were obtained from participants. Overall, 210 pregnant women were included. Random numbers were generated by random allocation software in binary blocks, and the pediatric neurologist assigned participants into intervention or control groups of equal numbers. The intervention group underwent 5 educational group sessions, 
each lasting for almost 45 minutes. The sessions were held during the third trimester of pregnancy (the first session), and then 2-6 weeks, 2-6 months, 6-9 months, and 9-12 months after delivery. The educational content of each session was adopted from the Persian version of the Care for Child Development (CCD)-2012 manual (Table 1) (16). In the intervention group, mothers were trained on how to play and communicate with their children based on the children's age. We used training materials including educational slides and toys for better education of mothers. Parents should engage in play and communication activities to encourage their children's learning, according to CCD recommendations. They also learn how to be sensitive to the needs of children and respond appropriately to address their needs through play and communication. Children 's survival, as well as their healthy growth and development, are enhanced by these basic caregiving skills. The training sessions were held by a Pediatric neurologist. The control group underwent routine education on child care, suggested by WHO, which is currently implemented in most of the primary health care centers in the country by using pamphlets, as well as general skills training sessions such as sessions on breastfeeding encouragement. 
Table 1

Topics of parent training sessions based on Care for Child Development (CCD) manual

$\begin{array}{lll}\text { Sessions } & \begin{array}{l}\text { Elements } \\ \text { of } \\ \text { nurturing } \\ \text { care }\end{array} & \\ & \end{array}$

\begin{tabular}{|c|c|c|}
\hline $\begin{array}{l}\text { Session } \\
1\end{array}$ & Health & $\begin{array}{l}\text { Family planning, prevention, and cessation of smoking, alcohol and } \\
\text { substance use, antenatal care, childbirth care, prevention of mother to } \\
\text { child transmission of HIV, essential newborn care with extra care for small } \\
\text { and sick babies, postnatal care contact, kangaroo mother care for low } \\
\text { birth weight babies, maternal immunization, childhood immunization, care } \\
\text { for children living with developmental difficulties and disabilities, support } \\
\text { for parental mental health, early detection of illness or disabling } \\
\text { conditions (e.g., sight, hearing), timely, appropriate care-seeking for sick } \\
\text { children, integrated management of child illness }\end{array}$ \\
\hline
\end{tabular}

Session Nutrition Maternal nutrition, early initiation, and exclusive breastfeeding, 2 complementary feeding and transition to the family healthy diet, micronutrients as needed, deworming, growth monitoring and intervention when indicated, management of all forms of malnutrition
Session Safety and 3 security

Safe water, sanitation, prevention of child abuse and neglect, prevention and reduction of indoor and outdoor pollution, environments healthy, green, free of toxins, prevention of intimate partner and family violence, prevention of harsh punishment of children, safe play spaces in urban and rural areas
Session Responsive Skin-to-skin contact immediately after birth, affectionate and secure adult $4 \quad$ care caregiving in a family environment, guidance for children in daily activities and relationships with others, daily feeding and sleep routines, involvement of fathers, extended family and other partners, social support by families, community groups and faith communities

$\begin{array}{ll}\text { Session } & \text { Early } \\ 5 & \text { learning }\end{array}$
Responding to children's communication through vocalizations, facial expressions and gestures, language stimulation through talking and singing, encouragement to explore objects with guidance from caregivers, caregiver-child play and reading and story-telling groups, mobile toy and book libraries, quality daycare, and pre-primary education

\section{Outcome measures}

The main outcome of the present study was the children's development at 12 months of age. Morever, based on our literature review, after the trial registration, we decided to follow up the children's behavior at 18 months of age. We examined children's development in 3 key developmental domains of cognition, language, and motor by Bayley Scales Of Infant and Toddler Development-III (BSCID-III) test. It was validated in Persian and the reliability was assessed using Cronbach's alpha for internal consistency (cognition ( $r=0.79)$, language (receptive communication $(r=0.76)$, expressive communication $(r=0.81)$ ), motor (fine motor $(r=0.80)$, and gross motor scales $(r=0.81))$ ). The standardized Persian version of this questionnaire did not include the other 2 domains of social-emotional and adaptive of the English version of BSCID-III (17). The lower scores in each domain show delayed development in that field. Scores of $\geq$ 85 show normal developmental status. Scores of 70-84 show mild developmental delay, 55-69 show moderate developmental delay, and $<55$ show severe developmental delay(18). In our study, the test was 
performed by a certified healthcare provider, who was trained by the Iranian Ministry of Health and Medical Education as one of the staff for performing the BSID-III test in Iran. We also assessed children's behaviors by $\mathrm{CBCL} / 1 \frac{1}{2}-5$, which was developed by Achenbach (19). It consists of 99 closed items and one open-ended item. Mothers completed the Persian version of $\operatorname{CBCL}(20,21)$, normalized and translated by Mohammad Esmaeel (22). In addition to a total problem score, CBCL contains 2 broadband scales (externalizing problems and internalising problems) and 8 narrowband syndrome scales including emotionally reactive, anxiety/depression, somatic complaints, withdrawal, sleep problems, attention problems, aggressive behavior, and other problems. The latter involves a range of heterogeneous problems including jealousy, disobedience, food refusal, overeating, being overweight, nail-biting, nightmares, etc. DSM-V scales include affective problems, anxiety problems, pervasive developmental problems, attention-deficit/ hyperactivity problems, and oppositional defiant problems.

Good test-retest reliability was found with correlation coefficients ranging from 0.37 to 0.91 for each item. The average test-retest reliability coefficients for the total competence score and the total problems score were 0.80 and 0.79 , respectively (23). In the test re-test analyses conducted by Achenbach et al. (24) with a two-week interval, a test-retest coefficient of 0.87 was reported for behavioral problems.

Sociodemographic data were collected from the mothers in both groups at the time of enrollment. The number of children, educational level of parents, parental ages, and their income, history of paternal smoking, infant's gender, Apgar scores, gestational age, and delivery type were collected.

\section{Statistical analysis}

Continuous variables were expressed as means \pm standard deviation (SD), and categorical data as number (percentage). We assessed the normality of data by the Kolmogorov-Smirnov test. Comparisons between means of continuous variables in the intervention and control groups were performed using independent Student t-test for variables with normal distributions, and the Mann-Whitney test for those with non-normal distributions. We used the Chi-square test to assess the difference in the distribution of the categorical variables between intervention and control groups. We calculated the adjusted median difference between the intervention and control groups by median regression models. The models were adjusted with maternal and paternal age and educational levels, paternal cigarette smoking, preterm labor, type of delivery, and child's gender. All analyses followed intention-to-treat (ITT) principles with participants analyzed in the group to which they were originally randomized, regardless of what treatment they received.

Data analyses were performed using the statistical software STATA 12.0 (STATA Corp, College Station, Texas, USA). P-values of less than 0.05 were considered statistically significant.

\section{Results}

Among 210 participants, data of 181 children were complete and used in the present study (80 children in the intervention group and 101 children in the control group). We lost 23 participants in the intervention 
group because of the COVID-19 outbreak and social distance. Moreover, we lost to follow-up 2 and 4 children in the intervention and control group, respectively (Fig. 1). In total, $51.9 \%$ of them were boys. Table 2 shows the maternal, parental, and child characteristics by the group. Maternal and paternal age in the control group was significantly lower than intervention group $(P<0.05)$. The Kolmogorov-Smirnov test for the cognitive score, language score, and motor score, and all CBCL scales were significant $(\mathrm{P}<$ $0.05)$, thus the distribution of these variables was not normal. The frequencies of children with normal (score $\geq 85$ ), mild (score $=70-84$ ), and moderate (score $=55-69$ ) neurodevelopmental delay, measured by the BSID-III, are presented in Table 3. The majority of children had scores $\geq 85$ in all domains (cognitive, language, and motor domains). The difference of proportions in the two groups of intervention and control was not significant in all domains $(P>0.05)$. The median for all scores was more than 100 in both intervention and control groups. The adjusted median differences between intervention and control groups using median regression were not significant for all domains (Table 3). Table 4 shows the results of CBCL in intervention and control groups at 18 months of age. The median of CBCL scales in the intervention group was significantly lower than the control group for anxiety/depression, attention problems, internalising behaviors and, the total score in the syndrome scale, as well as anxiety problems, and oppositional defiant problems in DSM-oriented scales $(P<0.05)$. The adjusted median differences were significantly lower for intervention group than control group for attention problems $(-3.38 ; \mathrm{SE}=1.59$; $P=0.035)$, anxiety problems $(-2.28 ; S E=1.03 ; P=0.007)$ and pervasive developmental problems $(-5 ; S E=$ $1.16 ; P<0.001)$. 
Table 2

Parents and children's characteristics

\begin{tabular}{|c|c|c|c|c|}
\hline & & Intervention & Control & P-value \\
\hline \multicolumn{5}{|l|}{ Parents } \\
\hline Maternal age, mean(SD) & & $31.99(4.72)$ & $29.48(5.17)$ & 0.001 \\
\hline Paternal age, mean(SD) & & $37.23(8.49)$ & $34.07(5.09)$ & 0.002 \\
\hline \multirow[t]{4}{*}{ Maternal education } & $\mathrm{n}(\%)$ & & & \\
\hline & Secondary school and less & $8(10.1 \%)$ & $13(12.9 \%)$ & 0.847 \\
\hline & High school or diploma & $35(44.3 \%)$ & $44(43.6 \%)$ & \\
\hline & University education & $36(45.6 \%)$ & $44(43, .6 \%)$ & \\
\hline \multirow[t]{4}{*}{ Paternal education } & $\mathrm{n}(\%)$ & & & \\
\hline & Secondary school and less & $25(31.6 \%)$ & $33(33.7 \%)$ & 0.740 \\
\hline & High school or diploma & $34(43 \%)$ & $45(45.9 \%)$ & \\
\hline & University education & $20(25.3 \%)$ & $20(20.4 \%)$ & \\
\hline \multicolumn{5}{|l|}{ Income, n(\%) } \\
\hline & low & $14(17.5 \%)$ & $28(27.7 \%)$ & 0.090 \\
\hline & moderate & $54(67.5 \%)$ & $66(65.3 \%)$ & \\
\hline & high & $12(15 \%)$ & $7(6.9 \%)$ & \\
\hline \multicolumn{5}{|l|}{ Paternal smoking } \\
\hline & No & $68(85 \%)$ & $85(84.2 \%)$ & 0.876 \\
\hline & Yes & $12(15 \%)$ & $16(15.8 \%)$ & \\
\hline \multicolumn{5}{|l|}{ Children } \\
\hline Gender, $\mathrm{n}(\%)$ & girl & $41(51.3 \%)$ & $53(52.5 \%)$ & 0.870 \\
\hline Gestational age, $\mathrm{n}(\%)$ & $<37$ week & $1(1.3 \%)$ & $5(5 \%)$ & 0.167 \\
\hline Delivery Type, n(\%) & Cesarean & $41(51.3 \%)$ & $56(55.4 \%)$ & 0.268 \\
\hline
\end{tabular}


Table 3

Results of BCID-III in intervention and control groups at 12 month of age

\begin{tabular}{|c|c|c|c|c|c|c|c|}
\hline & & Intervention & Control & & $\begin{array}{l}\text { Adjusted } m \\
\text { differences }\end{array}$ & dian & \\
\hline & & $(n=80)$ & $(n=101)$ & $\mathbf{P}$ & coefficient & SE & $P^{a}$ \\
\hline $\begin{array}{l}\text { Cognitive } \\
\text { score }\end{array}$ & $\begin{array}{l}\text { Median } \\
\text { (IQR) }\end{array}$ & $\begin{array}{l}105(100- \\
115)\end{array}$ & $\begin{array}{l}110(100- \\
120)\end{array}$ & 0.099 & -4.22 & 2.51 & 0.095 \\
\hline & $70-84$ & $1(1.3 \%)$ & $3(3 \%)$ & 0.423 & & & \\
\hline & $\geq 85$ & 79 (98.8\%) & 96 (97\%) & & & & \\
\hline $\begin{array}{l}\text { Language } \\
\text { score }\end{array}$ & $\begin{array}{l}\text { Median } \\
\text { (IQR) }\end{array}$ & $\begin{array}{l}\text { 112(103- } \\
118)\end{array}$ & $\begin{array}{l}112(103- \\
118)\end{array}$ & 0.444 & -1.92 & 2.52 & 0.446 \\
\hline & $70-84$ & $1(1.3 \%)$ & $0(0 \%)$ & 0.982 & & & \\
\hline & $\geq 85$ & 79 (98.8\%) & $100(100 \%)$ & & & & \\
\hline Motor score & $\begin{array}{l}\text { Median } \\
\text { (IQR) }\end{array}$ & $103(97-110)$ & $\begin{array}{l}\text { 107(91- } \\
112)\end{array}$ & 0.957 & -1.09 & 2.41 & 0.652 \\
\hline & $55-69$ & $0(0 \%)$ & $1(1 \%)$ & 0.480 & & & \\
\hline & $70-84$ & 7 (8.9\%) & $8(8.1 \%)$ & & & & \\
\hline & $\geq 85$ & $72(91.1 \%)$ & $90(90.9 \%)$ & & & & \\
\hline $\begin{array}{l}\text { a Adjusted by } \\
\text { paternal smc }\end{array}$ & $\begin{array}{l}\text { aternal an } \\
\text { g (cigaret }\end{array}$ & $\begin{array}{l}\text { ternal age and } \\
\text { nd gender. }\end{array}$ & ucational leve & gestatic & al age, types & f deli & \\
\hline BCID-III : Bay & Scales Of & nt and Toddler & evelopment-III & & & & \\
\hline
\end{tabular}


Table 4

Results of $\mathrm{CBCL}$ in intervention and control groups at 18 months of age

Intervention Control $\quad \begin{aligned} & \text { Adjusted median } \\ & \text { differences }\end{aligned}$

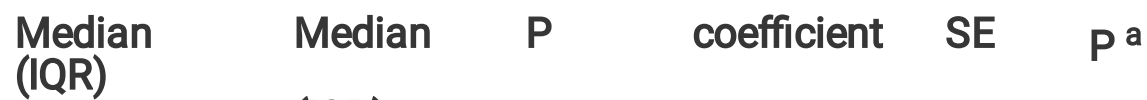

(IQR)

CBCL syndrome scales

Emotionally reactive

$\begin{array}{llll}42(35-46) & \begin{array}{l}42(35- \\ 46)\end{array} & 0.120 & 0\end{array}$

$1.23 \quad 1$

Anxiety/depression

$\begin{array}{ll}42(38-53) & 46(42 \\ 53)\end{array}$

$\mathbf{0 . 0 1 1}-2.47$

$2.04 \quad 0.227$

Somatic complaints

$\begin{array}{ll}35(35-44) & 40(35 \\ 44)\end{array}$

$0.182-1.61$

$1.63 \quad 0.326$

Withdrawn

$\begin{array}{ll}40(40-40) & 40(40 \\ 40)\end{array}$

0.162

$\begin{array}{ll}48(48-52) & 52(44- \\ & 57)\end{array}$

$\begin{array}{ll}48(48-52) & 52(44- \\ & 57)\end{array}$

Sleep problems

$0.182 \quad-1.47$

1.00

0.145

Attention problems

$\begin{array}{ll}35(35-41) & 41(35- \\ 46)\end{array}$

$\mathbf{0 . 0 4 3}-3.38$

1.5

0.035

Aggressive behavior

$\begin{array}{ll}40(37-43) & 40(37- \\ 46)\end{array}$

$0.343 \quad-0.96$

$1.23 \quad 0.436$

Other problems

$\begin{array}{ll}42(40-48) & 44(41- \\ 51)\end{array}$

$0.074 \quad-1.81$

1.56

0.247

Internalising behaviors

$\begin{array}{ll}38(36-41) & 40(37- \\ & 43)\end{array}$

$\mathbf{0 . 0 0 3}-1.87$

0.96

0.052

Externalizing behaviors

$38(35-43)$

39)(37-

48)

Total score

$43(39-51)$

$47(41-$

$0.009-3.63$

$0.077 \quad-0.97$

$1.46 \quad 0.508$

56)

CBCL DSM-oriented scales

Affective problems

$\begin{array}{ll}42(35-42) & 42(35- \\ 46)\end{array}$

$0.655 \quad 0.41$

$\begin{array}{ll}1.80 & 0.818\end{array}$

Anxiety problems

$\begin{array}{ll}43(40-46) & 46(40- \\ & 50)\end{array}$

$\mathbf{0 . 0 1 2}-2.82$

$\begin{array}{ll}1.03 & 0.007\end{array}$

Pervasive developmental

problems

$\begin{array}{llllll}35(35-40) & \begin{array}{l}40(35- \\ 40)\end{array} & 0.110 & -5.00 & 1.16 & < \\ & & & & 0.001 \\ 41(35-47) & \begin{array}{l}41(37- \\ 47)\end{array} & 0.280 & -0.73 & 1.94 & 0.707 \\ & & & & & \end{array}$

Attention deficit/ hyperactivity problems 
Oppositional defiant problems

41(35-44)

41

0.0120

1.15

1

a Adjusted by maternal and paternal age and educational levels, preterm labor, types of delivery, paternal smoking (cigarette), and gender.

CBCL: Child Behavior Checklist

\section{Discussion}

In the present study, educating mothers about the CCD recommendations in a group setting did not lead to the better developmental status of children in the intervention group compared to the control group. There were some significant differences between groups in the children's behavior subscale, including attention problems in the syndrome-oriented scale, as well as anxiety problems and pervasive developmental problems on the DSM-V-oriented scale. However, no statistically significant difference was observed between the intervention and control group in BSID-III scores.

To the best of our knowledge, this is the first study in a developing country in a group setting, focusing on the behavior as well as developmental domains in children in a parenting intervention program. Most studies in low or middle-income countries have merely assessed the developmental outcomes, not the children's behaviors $(8,25-29)$. As noted above, we conducted CCD sessions for parents in a group setting. Only one recently published cluster randomized clinical trial specifically compared the effectiveness of weekly home visits to weekly mother-child group sessions in rural India (14). Although we found no significant differences in cognitive, language, and motor development between intervention and control groups, Grantham-McGregor et al. revealed that group sessions were as effective as home visits in improving children's cognition and language, while both delivery models similarly had null impacts on children's motor, socioemotional, and behavior development in 1449 participants in India(14). This finding might be because of the program duration, cultural context, risk profiles of the population, and the available resources in the health care system. Since cost analysis revealed that the group-based model required a quarter of the costs compared to home visiting $(30,31)$, further studies are needed in this regard to discover the efficacy of parenting interventions through group sessions on the children's development and behaviors, particularly in low or middle-income countries.

Our finding on the association of children's behaviors to parenting interventions is consistent with the pooled results of a meta-analysis that showed parenting interventions reduce behavior problems $(\mathrm{SMD}=$ $-0.13,95 \% \mathrm{Cl}:-0.18,-0.08, \mathrm{P}<0.001 ; \mathrm{I} 2=53 \%, \mathrm{P}<0.001)(31)$. We did not find significant impacts of parenting interventions on ECD, however Jeong et al. indicated positive benefits of parenting interventions on children's cognitive development (SMD $=0.32,95 \% \mathrm{Cl}: 0.23,0.40, p<0.001)$, language development $(\mathrm{SMD}=0.28,95 \% \mathrm{Cl}: 0.18$ to $0.37, p<0.001)$, and motor development $(\mathrm{SMD}=0.24,95 \% \mathrm{Cl}: 0.15$ to $0.32, p$ $<0.001$ ) (31). The effect sizes are between 0.1 to 0.3 , which indicate small effect sizes (32). The inconsistent results might arise from the small sample size in our study. 
Identifying primary preventative interventions that would be effective and feasibly- delivered at these levels is helpful to decision-makers in the pursuit of reducing the burden of neurodevelopmental disorders and behavioral problems in low- and middle-income countries as it highlights where resources should be allocated (15). We speculate that CCD recommendations may be more effective for children $>18$ months as the mean age of children in our study was lower compared to some previous studies. A long-term follow-up is needed to figure this out. Moreover, we assume that educational group sessions may not be very effective among the Iranian population due to low teamwork ability in Iranians. However, the result of our study is not conclusive and further studies are needed in this regard.

There are some limitations to the present study that may have affected our findings. First, although the recruitment was randomized, mean maternal and paternal age at the time of child delivery were statistically significantly lower in the control group compared to the group that received the intervention. We speculate the older age of both parents in the intervention group might have affected our findings, as older parents may have less time and energy to spend and play with the child and may not be as responsive as younger parents to the child (33). Second, the number of children in the intervention and control groups was not equal. Although we approached an equal number of participants in each group, we lost a considerable number due to the COVID-19 outbreak. Many mothers in the intervention group were not willing to participate in the sessions anymore because of social distancing rules. Third, we were not able to assess parents' knowledge before and after the intervention, and their adherence to CCD instructions due to the limited resources. Fourth, in this study, we just involved mothers in group sessions. Despite the observational evidence that fathers are critically important for ECD (34), we could not involve fathers in our parenting program due to their work time as well as low compliance for the study. Despite these limitations, this study has focused on children's behavior during infancy and early childhood. Most parenting programs for behavioral development to date have been commonly delivered to preschool-aged children rather than young children during the earliest years of life and our information in early childhood was scarce $(15,35-37)$. Moreover, we represented the child's behavior through a valid and reliable tool, while several previous studies reported no details regarding the reliability or validity of the measurement tool for behavioral problems (31). Another strength of the current study is its novelty in developing countries and the first study of its kind in the region.

\section{Conclusion}

In the present trial, delivering parenting interventions through CCD group sessions had significant effects on several child's behavior domains, but not on their development. Although CCD is known to improve children's development and behaviors, the feasible method of its delivery to a large population, especially in developing countries, remains to be determined. Longitudinal studies on a large sample of children are necessary in this regard.

\section{Abbreviations}

BSCID-III: Bayley scales of infant and toddler development-III 
CBCL: Children behavior checklist

CCD: Care for child development

ECD: Early child development

SD: Standard deviation

SE: Standard error

ITT: Intention-to-treat

\section{Declarations}

\section{Consent for publication}

Not applicable

\section{Availability of data and materials}

The datasets used and/or analyzed during the current study are available from the corresponding author on reasonable request.

\section{Competing interests}

The authors declare that they have no competing interests.

\section{Funding}

This work was supported by Isfahan University of Medical Sciences (Grant number: 297001).

\section{Authors' contributions}

O.Y and R.K designed the study SS.D, N.H, M.A, M.P and M.B contributed to data collection. M.Kh performed the statistical analysis. M.B, N.B, and Sh.B wrote the first draft of the manuscript. O.Y and R.K edited it. All authors reviewed the manuscript.

\section{Acknowledgements}

The authors wish to acknowledge the cooperation and support of all the staff of the Research Institute for Primordial Prevention of Non-Communicable Disease for the time and effort they devoted to the study.

Ethical statement (approval ,guideline, informed consent) 
This randomized controlled trial was approved by the ethics committee of Isfahan University of Medical Sciences (ID: IR.MUI.RESEARCH.REC.1397.092), and has therefore been performed in accordance with the ethical standards laid down in the 1964 Declaration of Helsinki and its later amendments. The study protocol was explained to participants and written informed consent were obtained from participants.

\section{References}

1. Lu C, Black MM, Richter LMJTLGH. Risk of poor development in young children in low-income and middle-income countries: an estimation and analysis at the global, regional, and country level. 2016;4(12):e916-e22.

2. Walker S, Wachs T, Gardner JM, Lozoff B, Wasserman G, Pollitt E, et al. International Child Development Steering Group: Child development: risk factors for adverse outcomes in developing countries. 2007;369(9556):145-57.

3. Walker SP, Wachs TD, Grantham-McGregor S, Black MM, Nelson CA, Huffman SL, et al. Inequality in early childhood: risk and protective factors for early child development. Lancet. 2011;378(9799):1325-38.

4. Britto PR, Lye SJ, Proulx K, Yousafzai AK, Matthews SG, Vaivada T, et al. Nurturing care: promoting early childhood development. Lancet. 2017;389(10064):91-102.

5. Lucas JE. Care for Child Development: A Framework for Monitoring and Evaluating the WHO/UNICEF Intervention: UNICEF; [Available from: https://www.unicef.org/media/91196/file/7-Framework-forME.pdf.

6. Ara G, Khanam M, Papri N, Nahar B, Kabir I, Sanin KI, et al. Peer Counseling Promotes Appropriate Infant Feeding Practices and Improves Infant Growth and Development in an Urban Slum in Bangladesh: A Community-Based Cluster Randomized Controlled Trial. Curr Dev Nutr. 2019;3(7):nzz072.

7. Feil EG, Baggett K, Davis B, Landry S, Sheeber L, Leve C, et al. Randomized control trial of an internetbased parenting intervention for mothers of infants. Early Child Res Q. 2020;50(Pt 1):36-44.

8. Galasso E, Weber AM, Stewart CP, Ratsifandrihamanana L, Fernald LCH. Effects of nutritional supplementation and home visiting on growth and development in young children in Madagascar: a cluster-randomised controlled trial. Lancet Glob Health. 2019;7(9):e1257-e68.

9. Hamadani JD, Mehrin SF, Tofail F, Hasan MI, Huda SN, Baker-Henningham H, et al. Integrating an early childhood development programme into Bangladeshi primary health-care services: an openlabel, cluster-randomised controlled trial. 2019;7(3):e366-e75.

10. Weisleder A, Cates CB, Dreyer BP, Berkule Johnson S, Huberman HS, Seery AM, et al. Promotion of Positive Parenting and Prevention of Socioemotional Disparities. Pediatrics. 2016;137(2):e20153239.

11. Anzman-Frasca S, Paul IM, Moding KJ, Savage JS, Hohman EE, Birch LL. Effects of the INSIGHT Obesity Preventive Intervention on Reported and Observed Infant Temperament. Journal of 
developmental and behavioral pediatrics: JDBP. 2018;39(9):736-43.

12. Hepworth AD, Berlin LJ, Martoccio TL, Cannon EN, Berger RH, Harden BJJPS. Supporting infant emotion regulation through attachment-based intervention: A randomized controlled trial. 2020;21(5):702-13.

13. Eddy JM, Shortt JW, Martinez CR, Jr., Holmes A, Wheeler A, Gau J, et al. Outcomes from a Randomized Controlled Trial of the Relief Nursery Program. Prev Sci. 2020;21(1):36-46.

14. Grantham-McGregor S, Adya A, Attanasio O, Augsburg B, Behrman J, Caeyers B, et al. Group Sessions or Home Visits for Early Childhood Development in India: A Cluster RCT. Pediatrics. 2020;146(6).

15. McCoy DC, Salhi C, Yoshikawa H, Black M, Britto P, Fink G. Home-and center-based learning opportunities for preschoolers in low-and middle-income countries. Children and Youth Services Review. 2018;88:44-56.

16. Organization WH. Care for child development: improving the care of young children2012. $152 \mathrm{p}$.

17. Soleimani F, Azari N, Vameghi R, Sajedi F, Shahshahani S, Karimi H, et al. Is the Bayley Scales of Infant and Toddler Developmental Screening Test, Valid and Reliable for Persian Speaking Children? Iranian journal of pediatrics. 2016;26(5).

18. Celik P, Sucakli IA, Yakut HI. Which Bayley-III cut-off values should be used in different developmental levels? Turkish journal of medical sciences. 2020;50(4):764-70.

19. Achenbach TM. The classification of children's psychiatric symptoms: a factor-analytic study. Psychol Monogr. 1966;80(7):1-37.

20. Meybodi FA, Mohammadkhani P, Pourshahbaz A, Dolatshahi B, Mousavi ME, Heydari HJMEJoFM. Psychometric Properties of the Persian Version of the Emotion Regulation Checklist. 2018;7(10):187.

21. Pourhossein R, Habibi M, Ashoori A, Ghanbari N, Riahi Y, Ghodrati SJJoFoMH. Prevalence of behavioral disorders among preschool children. 2015;17(5):234-9.

22. Mohammad-Esmail EJTECRI. Guide form for measure system of preschool age's children $1-5$ years experience in Tehran. 2009:108 - 19.

23. Achenbach TM, Rescorla L. Manual for the ASEBA adult forms \& profiles. Burlington, VT: University of Vermont, Research Center for Children, Youth ...

24. Achenbach TM, Dumenci L, Rescorla LA. DSM-oriented and empirically based approaches to constructing scales from the same item pools. J Clin Child Adolesc Psychol. 2003;32(3):328-40.

25. Abessa TG, Worku BN, Wondafrash M, Girma T, Valy J, Lemmens J, et al. Effect of play-based familycentered psychomotor/psychosocial stimulation on the development of severely acutely malnourished children under six in a low-income setting: a randomized controlled trial. BMC Pediatr. 2019;19(1):336.

26. Aboud FE, Akhter S. A cluster-randomized evaluation of a responsive stimulation and feeding intervention in bangladesh. Pediatrics. 2011;127(5):e1191-7.

27. Aboud FE, Singla DR, Nahil MI, Borisova I. Effectiveness of a parenting program in Bangladesh to address early childhood health, growth and development. Soc Sci Med. 2013;97:250-8. 
28. Frongillo EA, Nguyen PH, Saha KK, Sanghvi T, Afsana K, Haque R, et al. Large-Scale Behavior-Change Initiative for Infant and Young Child Feeding Advanced Language and Motor Development in a Cluster-Randomized Program Evaluation in Bangladesh. J Nutr. 2017;147(2):256-63.

29. Abimpaye M, Dusabe C, Nzabonimpa JP, Ashford R, Pisani LJIJoBD. Improving parenting practices and development for young children in Rwanda: Results from a randomized control trial. 2020;44(3):205-15.

30. Dodge KA, Goodman WB, Bai Y, Murphy RA, O'Donnell K. Maximizing the return on investment in early childhood home visiting through enhanced eligibility screening. Child abuse \& neglect. 2021;122:105339.

31. Jeong J, Franchett EE, Ramos de Oliveira CV, Rehmani K, Yousafzai AK. Parenting interventions to promote early child development in the first three years of life: A global systematic review and metaanalysis. PLoS Med. 2021;18(5):e1003602.

32. Cohen J, editor Quantitative methods in psychology: A power primer. Psychological bulletin; 1992: Citeseer.

33. Silverstein M, Gans D, Lowenstein A, Giarrusso R, Bengtson VL. Older parent-child relationships in six developed nations: Comparisons at the intersection of affection and conflict. Journal of Marriage and Family. 2010;72(4):1006-21.

34. Jeong J, McCoy DC, Yousafzai AK, Salhi C, Fink G. Paternal Stimulation and Early Child Development in Low- and Middle-Income Countries. Pediatrics. 2016;138(4).

35. Barlow J, Bergman H, Kornor H, Wei Y, Bennett C. Group-based parent training programmes for improving emotional and behavioural adjustment in young children. Cochrane Database Syst Rev. 2016(8):CD003680.

36. Jeong J, Obradović J, Rasheed M, McCoy DC, Fink G, Yousafzai AK. Maternal and paternal stimulation: Mediators of parenting intervention effects on preschoolers' development. Journal of Applied Developmental Psychology. 2019;60:105-18.

37. Rincón P, Cova F, Saldivia S, Bustos C, Grandón P, Inostroza C, et al. Effectiveness of a positive parental practices training program for Chilean preschoolers' families: a randomized controlled trial. Frontiers in psychology. 2018;9:1751.

\section{Figures}




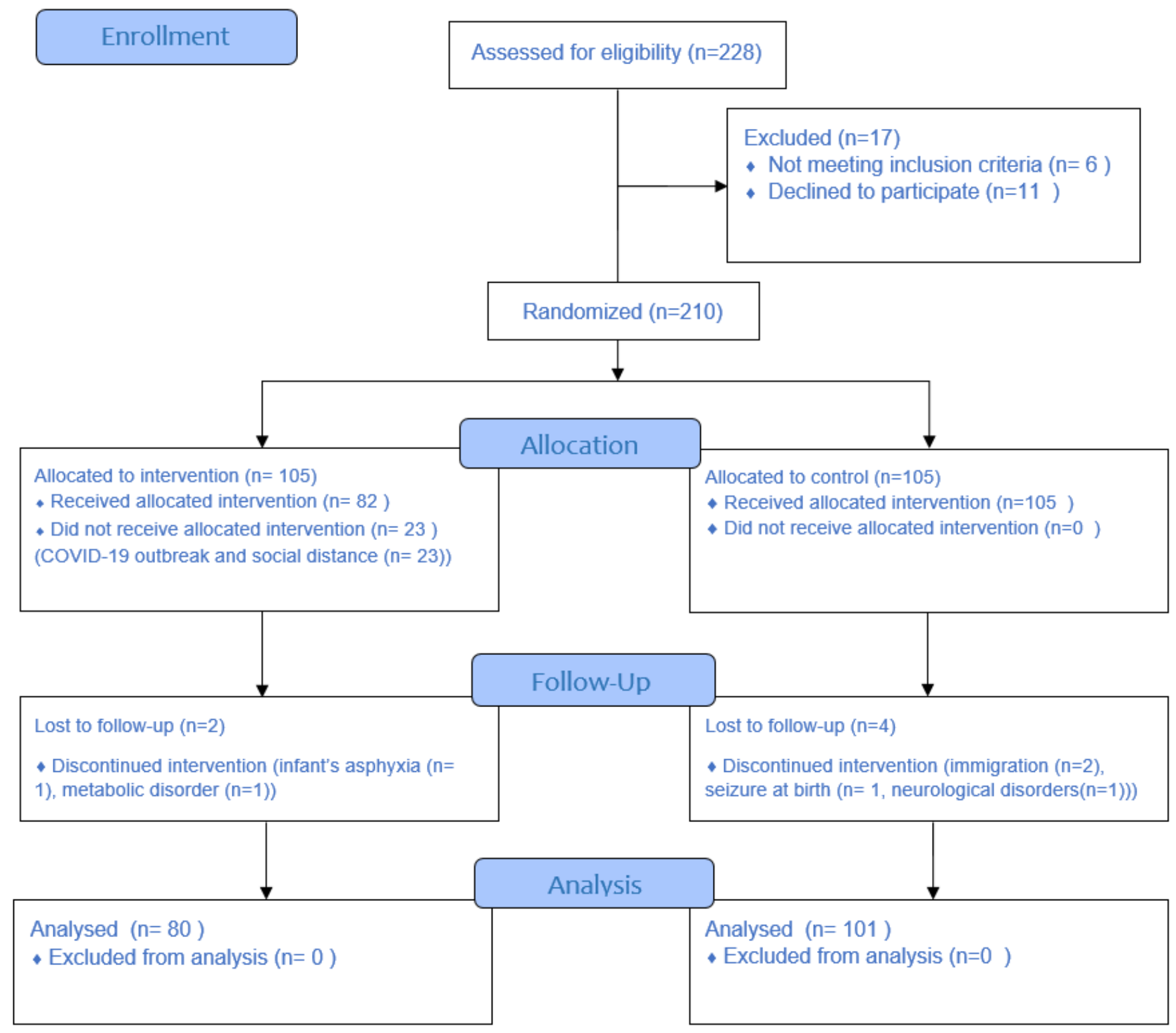

\section{Figure 1}

Flow diagram of the trial 